\title{
The effect of risk on supply chain cooperation: Evidence from Vietnam agriculture
}

\author{
Quang Bach Tran ${ }^{a *}$, Thi Bich Thuy Nguyen ${ }^{a}$, Thi Yen Nguyen ${ }^{a}$, Van Hao Trana, Thi Xuan Loc Nguyen \\ and Thi Cam Thuong Hoang ${ }^{a}$
}

${ }^{a}$ Lecturer, Faculty of Economics, Vinh University, Vietnam

${ }^{b}$ Deputy, Personnel Division, Vinh University, Vietnam

\section{A B S T R A C T}

\section{Article history:}

Received September 18, 2020

Received in revised format May

8,2021

Accepted September 62021

Available online

September 62021

\section{Keywords:}

Risk

Trust

Commitment

Opportunistic Behaviour

Supply Chain Cooperation

The Agricultural Supply Chain

\begin{abstract}
The study aims to test the impact of risk on supply chain cooperation in the agriculture sector in Vietnam. The research paper used the quantitative research method through analysing structural equation modelling (SEM), with a dataset of 518 observations. The survey subject is the experienced and knowledgeable manager in supply chain management in the agricultural sector. The result found that risk has impacted not only directly and negatively on the supply chain cooperation but also indirectly through intermediary factors, namely commitment and the participant's opportunistic behaviour. In addition, the study has also proved that in some cases, the participant's dependency mentality in work and opportunistic behaviour lead to the opposite impact of commitment on trust and level of supply chain cooperation in agriculture. Based on this result, the study also makes recommendations to enhance the effectiveness of the supply chain cooperation in the agricultural sector in Vietnam. The findings contributed to both theory and practice. It pointed out the impact of risk on the supply chain cooperation in the agricultural sector, as well as the mediating role of commitment and opportunistic behaviour in this relationship.
\end{abstract}

(C) 2022 Growing Science Ltd. All rights reserved.

\section{Introduction}

In the context of the highly competitive and globalized business age, manufacturing facilities have realized early on that to gain and maintain a competitive advantage, they must provide the best value to their customers at the lowest cost. Customers are becoming more and more strict with their demands for faster response times, shorter product cycles and higher quality products and services. Over the past decade, to ensure supply chain efficiency and responsiveness and take advantage of resources and knowledge of suppliers and their customers, the enterprise has been looking for opportunities to work with supply chain partners (Cao \& Zhang, 2011). Collaboration plays a fundamental role in boosting product development, reducing development costs, improving technology and improved product quality (Walter, 2003). Supply chain partners have a growing need to be dynamic with high responsiveness to add value to customers. Business goals seem difficult to achieve by an individual organization but can be easily achieved through collaborative supply chain relationships. Therefore, cooperative behaviour and activities in supply chain management have gained considerable importance (Kocoglu et al., 2011). Lambert et al. (1998) define a supply chain as an association of companies to bring products and services to the market. The relationship between supply chain partnerships has received considerable attention in recent years (Samaddar \& Kadiyala, 2006). Collaboration in the supply chain leads to improved performance in the supply chain (Vereecke \& Muylle, 2006). The recent research works have mentioned cooperation in the supply chain, determinants of the cooperation effectiveness of the supply chain in the agricultural sector. According to Lee and Whang (2000), behavioural uncertainty makes it difficult to predict and understand a partner's actions. Both companies need to consider the partnership as a growth strategy and fully committed to trusting each other when acting in the common good (Fawcett et al., 2012). The paper by Fawcett et al. (2012); Nyaga et al. (2010) refer to trust and conclude that the positive trust, attitude or expectation of one 
party about the ability of another party's actions or results have an impact on supply chain cooperation. The agricultural sector in Vietnam plays a fundamental role in the country's economic growth. Vietnam's policies are highly appreciated in motivating to promote potentials and advantages of the agricultural sector, which turns Vietnam from a recipient of food aid to a food exporting country. However, the agriculture sector's development in Vietnam is disproportionate, which is reflected by the restructuring of the agriculture industry, low export value, small production scale, limited product quality, few main agricultural products, etc. One of the reasons is that businesses and agricultural producers have not been closely participating in the supply chain. The link and cooperation between participants in the supply chain are still loose. Few organizations can attract, entice and lead or create closed production and supply chain processes from raw material purchasing, transportation, storage, marketing to consumption. Therefore, it has not taken advantage of opportunities to exploit the agricultural development strengths of each locality.

Based on the theoretical overview, the paper builds a research model and tests the impact of risk on supply chain cooperation in the agricultural sector in Vietnam. The result found that risk has impacted not only directly and negatively on the supply chain cooperation but also indirectly through intermediary factors, namely commitment and the participant's opportunistic behaviour. In addition, the study has also proved that in some cases, the participant's dependency mentality in work and opportunistic behaviour lead to the opposite impact of commitment on trust and level of supply chain cooperation in agriculture. Based on this result, the study also makes recommendations to enhance the effectiveness of the supply chain cooperation in the agricultural sector in Vietnam. The findings contributed to both theory and practice. It pointed out the impact of risk on the supply chain cooperation in the agriculture sector as the mediating role of commitment and opportunistic behaviour in this relationship. Therefore, the findings support managers and policymakers to gain a more comprehensive view of supply chain cooperation in the agriculture industry, which plays an essential role in making effective decisions, enhancing valuable values for agricultural products in Vietnam as in the world.

\section{Literature Review and Hypotheses}

\subsection{Literature Review}

Supply chain collaboration is defined in many ways and divided into two groups, which are process-focused and relationshipfocused. According to Mentzer et al. (2001); Stank et al. (2001); Manthou et al. (2004); Sheu et al. (2006), supply chain collaboration is a process in which partners work together towards common goals. Bowersox et al. (2003); Golicic et al. (2003) supposed that supply chain collaboration is the formation of close, long-term partnerships by members working together and sharing information, resources, and risks to accomplish common goals (Bowersox et al., 2003; Golicic et al., 2003). According to Juttner et al. (2003), risks in the supply chain are those related to information, transportation of materials and products from suppliers to final consumers, the mismatch between market supply and demand. There are many ways to classify the source of risk. Cavinato (2004) divides risk in the supply chain into five types: risk in physical flow, currency, information, partnerships and innovative opportunities for supply chain members. Juttner et al. (2003) divided risks in the supply chain into three groups: environmental risks due to the uncertainty of the business environment such as disasters, crises; organizational risks stemming from members of the supply chain such as malfunctions in production and distribution systems; and finally risks related to workers' strikes or errors from the structure and characteristics of the supply chain such as the lack of cooperation, linkage and sharing among members. Trust plays an essential role in the cooperative relationship between organizations (Bromiley \& Cummings, 1995; Sheu et al., 2006). From an economic point of view, trust leads to efficient transactions by reducing transaction costs (Bromiley \& Cummings, 1995). From the perspective of social exchange, trust exists in the social context in which supply chain partners generate social capital and influence economic activities (Uzzi, 1997). In both of these perspectives, trust is seen as a governance mechanism to reduce conflict, opportunism, and promote cooperation, further allowing firms to gain collaborative advantages and better corporate performance (Morgan \& Hunt, 1994). Morgan and Hunt (1994) suggested that commitment is the maximum effort to maintain the relationship between partners and is at the heart of all relations between the company and its partners. Commitment refers to the willingness of trading partners to make efforts to build and maintain relationships, suggesting a future direction in which companies strive to build relationships in the face of unforeseen problems (Nyaga et al., 2010). The behaviour of each individual or an organization includes two types: positive and negative. According to Nguyen et al. (2020), opportunistic behaviour is considered a negative form that is governed and determined by the perception, attitude, and capacity of individuals and organizations. The opportunistic behaviour leads to the breaking of commitments, violations of obligations and responsibilities required by the parties (Morgan \& Hunt, 1994). Opportunistic behaviour is related to individualism, based on self-seeking behaviour for individuals or organizations, which causes damage to partners and stakeholders, thereby inhibiting the market development

\subsection{Hypotheses}

\subsubsection{Risk and the Supply Chain Cooperation in the Agriculture Sector}

Supply chain cooperation brings many benefits, promoting the participant's development. However, this cooperation sometimes contains risks, which can stem from the market, the environment or the partners. The higher risk from the market 
is, the manufacturer must change products, volumes and orders frequently (Trkman \& McCormack, 2009). It will affect the supply of raw materials from suppliers to manufacturing enterprises. With the higher risk from the market, it is difficult for the Marketing department to coordinate smoothly with other departments such as the production department or the material supply department. Finally, fluctuating and changing market demand will obstruct manufacturers to identify market needs and feedback from customers, and it will also become harder to connect with customers (Calantone et al., 2003). Given the context of the agricultural sector in Vietnam, the relationship between risk and supply chain cooperation is expected negative, we hypothesize that:

$\mathbf{H}_{1}$ : Risks have negatively impacted the supply chain cooperation in the agriculture sector in Vietnam (see Fig. 1).

\subsubsection{Risk and the Participant's Trust in the Agricultural Supply Chain}

The delivery problems such as failure to deliver on time, delay or destruction of supply contracts will affect the coordination process between departments in the organization as between the procurement department and the production department (Frohlich \& Westbrook, 2001). It also makes it difficult for manufacturing enterprises to meet deadlines, quantity and quality for customers, which leads to a decrease in customers' trust and cooperation with manufacturers (Zsidisin, 2003). The hypothesis is showed as follows:

H2: Risks exert a negative impact on the participant's trust in the Vietnamese agricultural supply chain (see Fig. 1).

\subsubsection{The Participant's Trust and the Supply Chain Cooperation in the Agriculture Sector}

The underlying values and beliefs shared within a company are related to business activities in the supply chain (Boddy et al., 2000; Wuyts \& Geyskens, 2005). Trust brings many positive values, promotes solidarity and cooperation among organizations. For the most part, the long-term relationship between businesses will be based on the participant's trust. With the context in Vietnam, to test the relationship between belief and the supply chain cooperation in the agricultural sector, the authors hypothesize:

H3: The participant's trust exerts a positive impact on the supply chain cooperation in the agriculture sector in Vietnam (see Fig. 1).

\subsubsection{Risk and the Participant's Commitment in the Agricultural Supply Chain}

Risks in the supply chain may be due to the impact of politics, economy, society, natural environment, etc. The higher risks are when the supply chain is increasingly expanded and complex (Khan \& Burnes, 2007). With the higher risk from the market, the manufacturer must change products, volumes and orders frequently (Trkman \& McCormack, 2009). The hypothesis is proposed as follows:

$\mathbf{H}_{4}$ : Risks and the participant's commitment to the agricultural supply chain in Vietnam have a negative relationship (see Fig. 1).

\subsubsection{The Participant's Commitment and the Supply Chain Cooperation in the Agriculture Sector}

Commitment refers to the willingness of trading partners to make an effort to contribute based on their relationship and suggests a future direction in which companies work towards building a long-lasting relationship when many different problems occur (Chen \& Paulraj, 2004). To test the relationship between the participants' commitment and the supply chain cooperation in the agriculture industry in Vietnam, the authors hypothesize:

H5: The participant's commitment positively impacts the supply chain cooperation in the agriculture sector in Vietnam (see Fig. 1).

\subsubsection{Risk and the Participant's Opportunistic Behaviour in the Agricultural Supply Chain}

These risks are usually objective and beyond the control of each member of the chain and can create negative opportunistic behaviours (Tran et al., 2019). Therefore, members often tend to diversify their relationships to minimize the risk instead of enhancing cooperation, closely linking with a small number of partners, which minimize unwanted actions from partners (Chen \& Paulraj, 2004). With the context of the agricultural industry in Vietnam, to test the impact of risk on the opportunistic behaviour of participants in the agriculture supply chain, the hypothesis is showed as follows:

H6: Risk impacts positively the participant's opportunistic behaviour in the agricultural supply chain in Vietnam (see Fig. $1)$. 
Opportunistic behaviour is often associated negatively with risk in supply chain cooperation such as not satisfying the needs of partners or affecting the safety of enterprises (Zsidisin, 2003). The high-risk market is usually characterized by the regular changes and unpredictable of the customer's and institution's needs in their commitment. Businesses often find it difficult to do business when operating in such an environment (Trkman \& McCormack, 2009). Therefore, the authors hypothesize:

H7: The participant's opportunistic behaviour has a negative impact on the supply chain cooperation in the agriculture sector in Vietnam (see Fig. 1).

\subsubsection{The Participant's Commitment and Trust in the Agricultural Supply Chain}

Trust is one of the most widely accepted social norms in inter-organizational communication (Morgan \& Hunt, 1994). In his research, Kwon and Suh (2004) demonstrated a relationship between trust and commitment. A hypothesis is proposed as follows:

H8: The participant's commitment and trust have a positive relation in the agricultural supply chain in Vietnam (see Fig. 1).

\subsubsection{The Participant's Commitment and Opportunistic Behaviour in the Agricultural Supply Chain}

In the theoretical framework of marketing, Morgan and Hunt (1994) demonstrated a negative relationship between opportunistic behaviour and trust, which is the premise of the partner's commitment to a long-term relationship. Enhancing the commitment between participants in the supply chain will lead to a proactive mentality in the cooperation process, build trust, create more sustainable understanding and attachment. Thereby, it is essential for minimizing negative behaviours, improving the overall working efficiency of organizations. In the context of the agriculture sector in Vietnam, the relationship between these two factors is shown thorough by the research hypothesizes as follows:

H9: The participant's commitment has a negative impact on opportunistic behaviour in the agricultural supply chain in Vietnam (see Fig. 1).

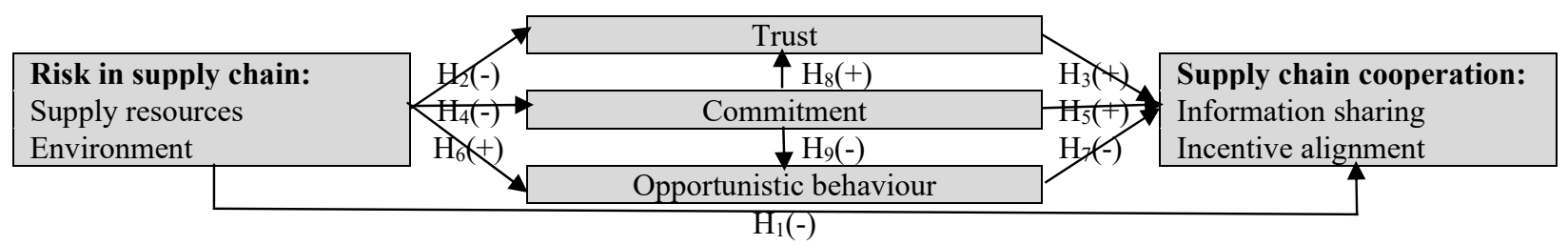

\section{Research Method}

Fig. 1. Proposed Research Model

\subsection{Research Scale}

Based on the theoretical overview, the paper has proposed a research model with an independent variable of Supply Chain Risk (SCR) consisting of (i) Risks from the supply sources (RS) and (ii) Risks from the environment (RE). The intermediate variables are Trust (TR), Commitment (COM) and Opportunity Behaviour (OPB). The dependent variable is the supply chain cooperation (SCC) which includes (i) Information Sharing (IS) and (ii) Incentive alignment (IA). The scale used in the study is a Likert scale with five levels (Strongly agree; Agree; Normal; Disagree; Strongly disagree). Indicators measuring variables are accommodated following the study sample characteristics from previous studies (see Table 1).

Table 1

Origin of the scale of variables

\begin{tabular}{|c|c|c|c|c|}
\hline No. & Variables & Abbreviation & \# of observations & Origin of the scale \\
\hline 1 & Risks from supply sources & $\mathrm{RS}$ & 5 & $\begin{array}{l}\text { Wagner \& Bode (2008) } \\
\text { Zhao \& cộng sự (2013 }\end{array}$ \\
\hline 2 & Risks from the environment & $\mathrm{RE}$ & 6 & $\begin{array}{l}\text { Wagner \& Bode (2008) } \\
\text { Zhao et al. }(2013)\end{array}$ \\
\hline 3 & Trust & TR & 5 & Morgan \& Hunt (1994) \\
\hline 4 & Commitment & $\mathrm{COM}$ & 7 & $\begin{array}{c}\text { Morgan \& Hunt (1994) } \\
\text { Torres (2012) }\end{array}$ \\
\hline 5 & Opportunistic behaviour & OPB & 5 & Katsikeas et al. (2009) \\
\hline 6 & Information sharing & IS & 10 & Togar \& Ramaswami (2005) \\
\hline 7 & Incentive alignment & IA & 6 & Togar \& Ramaswami (2005) \\
\hline
\end{tabular}




\subsection{Research Sample}

The sampling method is the non-probability convenience sampling method. Data were collected through stratified sampling relatively according to provinces and localities in Vietnam. The investigation objection is the experienced and knowledgeable manager in the supply chain operation management in the agriculture sector at enterprises in Vietnam. The sample size was 518 observations. The data collection process is implemented in two ways: face-to-face and online. The number of online votes collected is 327 , the number of usable votes is 293 . About the face-to-face survey, the number of sheets issued is 400 , the number of votes collected is 296 , the number of usable votes is 225 . The total number of valid sheets for analysis is 518 . According to Hair et al. (1998), for the reference of expected sample size, the minimum sample size is five times the total number of observed variables. With 44 observations in the manuscript, the research scale includes 518 samples to meet the analysis requirements. The data collection period is from May 2021 to August 2021.

\subsection{Data Processing}

The research paper has used the quantitative method. After data collection and cleaning, data has been processed through SPSS and AMOS programs. First, the authors have evaluated the scale's reliability by Cronbach's Alpha value ( $>0.7)$. Next, exploratory factor analysis (EFA) to determine "converging value" and "distinguishing value" of the scale is used with the requirement of Factor loading $>0.5$; Eigenvalue of factors $>=1$; KMO coefficient $>=0.5$ and $<=1$; Sig value. $<0.05$, and the percentage of variance extracted $>50 \%$. After that, AMOS software is utilized to evaluate the suitability of the research model through the CFA test. Finally, the authors have tested the research hypotheses by analysing the structural equation modelling (SEM) with the requirements of chi-square/df index $<5$ in case of sample size $>200$ (Kettinger et al., 1995); GFI, TLI, CFI > 0.8; RMSEA $<0.08$ (Taylor et al., 1993).

\section{Results and Discussion}

\subsection{Testing the Reliability of the Scale}

The test result of Cronbach's Alpha showed that the Cronbach's Alpha coefficients of all variables are $>0.7$, which is very high (see Table 2). However, the indicators RE6, IS1, IA6 have Cronbach's Alpha-if-Item-Deleted coefficients of 0.921, $0.845,0.874$ which are larger than the Cronbach's Alpha coefficient of the variable RE, IS, IA of $0.907,0.823,0.803$ respectively. Therefore, to increase the scale's reliability, the authors removed RE6, IS1, IA6.

Table 2

Evaluation of the reliability of the scale through Cronbach's Alpha coefficient

\begin{tabular}{clcc}
\hline No. & \multicolumn{1}{c}{ Variables } & Abbreviations & Cronbach's Alpha coefficient \\
\hline 1 & Risks from supply sources & RS & 0.870 \\
2 & Risks from the environment & RE & 0.921 \\
3 & Trust & TR & 0.911 \\
4 & Commitment & COM & 0.917 \\
5 & Opportunistic behaviour & OPB & 0.883 \\
6 & Information sharing & IS & 0.845 \\
7 & Incentive alignment & IA & 0.874 \\
\hline
\end{tabular}

\subsection{EFA}

After testing the scale's reliability, the authors have conducted exploratory factor analysis (EFA) for the independent, intermediate and dependent variables. With the group of independent variables and intermediate variables, the EFA test is carried out twice. The test result has shown that the factor loading coefficients are all $>0.5$, which demonstrates the appropriate correlation between the variables (indicators) and selected variables in the model. However, in the first analysis, due to not guaranteeing the "convergence value" of the same factor, COM2 is removed. The result of the second test shows that data is eligible for analysis because the variables' Eigenvalue value $>=1$; KMO coefficient $>=0.5$ and $<=1$; Sig value $<$ 0.05 , the percentage of variance extracted $>50 \%$ and satisfying two conditions that are "convergence value" (observed variables converge on the same factor) and "discriminatory value" (the distinction between observed variables) (see Table 3 \& 4).

Table 3

The EFA test's result for independent and intermediate variables

\begin{tabular}{cccccc}
\hline EFA test & $\begin{array}{c}\text { KMO } \\
\text { coefficient }\end{array}$ & P-value & $\begin{array}{c}\text { Extracted } \\
\text { variance }\end{array}$ & $\begin{array}{c}\text { Factor loading } \\
\text { factor }\end{array}$ & Conclusion \\
\hline $1^{\text {st }}$ & 0.887 & 0.000 & 71.271 & All $>0.5$ & Remove COM2 \\
$2^{\text {nd }}$ & 0.900 & 0.000 & 71.700 & All $>0.5$ & Ensure analysis requirements \\
\hline
\end{tabular}


Table 4

$\underline{\text { Rotation matrix in EFA test for the independent and intermediate variables }}$

\begin{tabular}{|c|c|c|c|c|c|}
\hline \multirow{2}{*}{ Indicator } & \multicolumn{5}{|c|}{ Component } \\
\hline & 1 & 2 & 3 & 4 & 5 \\
\hline COM7 & 0.892 & & & & \\
\hline COM5 & 0.804 & & & & \\
\hline COM6 & 0.801 & & & & \\
\hline COM3 & 0.789 & & & & \\
\hline COM4 & 0.760 & & & & \\
\hline COM1 & 0.697 & & & & \\
\hline RE2 & & 0.875 & & & \\
\hline RE4 & & 0.857 & & & \\
\hline RE5 & & 0.843 & & & \\
\hline RE1 & & 0.838 & & & \\
\hline RE3 & & 0.716 & & & \\
\hline TR1 & & & 0.840 & & \\
\hline TR3 & & & 0.835 & & \\
\hline TR2 & & & 0.817 & & \\
\hline TR4 & & & 0.816 & & \\
\hline TR5 & & & 0.738 & & \\
\hline OPB5 & & & & 0.814 & \\
\hline OPB2 & & & & 0.814 & \\
\hline OPB3 & & & & 0.803 & \\
\hline OPB4 & & & & 0.774 & \\
\hline OPB1 & & & & 0.748 & \\
\hline RS5 & & & & & 0.750 \\
\hline RS1 & & & & & 0.748 \\
\hline RS2 & & & & & 0.731 \\
\hline RS3 & & & & & 0.709 \\
\hline RS4 & & & & & 0.651 \\
\hline
\end{tabular}

The EFA test for the dependent variable is also conducted twice in which factor loading coefficients are all $>0.5$, which demonstrates the appropriate correlation between the variables (indicators) and selected variables in the model. However, in the first analysis, due to not guaranteeing the "convergence value" of the same factor, IS2 and IS3 are removed. The result of the second test shows that data is eligible for analysis because the variables' Eigenvalue value $>=1$; KMO coefficient $>=0.5$ and $<=1$; Sig value $<0.05$, the percentage of variance extracted $>50 \%$ and satisfying two conditions that are "convergence value" and "discriminatory value" (see Table $5 \& 6$ ).

\section{Table 5}

The EFA test's result for the dependent variable

\begin{tabular}{cccccc}
\hline EFA test & $\begin{array}{c}\text { KMO } \\
\text { coefficient }\end{array}$ & P-value & $\begin{array}{c}\text { Extracted } \\
\text { variance }\end{array}$ & $\begin{array}{c}\text { Factor loading } \\
\text { factor }\end{array}$ & Conclusion \\
\hline $1^{\text {st }}$ & 0.816 & 0.000 & 54.287 & All $>0.5$ & Remove IS2, IS3 \\
$2^{\text {nd }}$ & 0.855 & 0.000 & 57.406 & All $>0.5$ & Ensure analysis requirements \\
\hline
\end{tabular}

Table 6

Rotation matrix in EFA test for the dependent variable

\begin{tabular}{ccc}
\hline Indicator & \multicolumn{1}{c}{ Component } & 2 \\
\cline { 2 - 3 } & \multicolumn{1}{c}{$\mathbf{1}$} & \\
\hline IA3 & 0.874 & \\
IA4 & 0.844 & \\
IA2 & 0.812 & 0.764 \\
IA5 & 0.769 & 0.755 \\
IA1 & 0.744 & 0.725 \\
IS4 & & 0.710 \\
IS7 & & 0.656 \\
IS5 & & 0.623 \\
IS10 & & 0.622 \\
IS9
\end{tabular}


After analysing EFA and removing mismatch indicators, the study retested the scale's reliability. The result shows the Cronbach's Alpha coefficient of all variables is $>0.7$, which proves the reliability of the scale used in the model.

\section{3. $C F A$}

The result has demonstrated the model's suitability with Chi-square $=2065.787 ; \mathrm{df}=644$; Chi-square $/ \mathrm{df}=3.208(<3)$; $\mathrm{P}=$ $0.000 ; \mathrm{GFI}=0.843(>0.8)$; TLI $=0.879(>0.8) ; \mathrm{CFI}=0.889(>0.8)$; $\mathrm{RMSEA}=0.065(<0.08)$.

\subsection{SEM Analysis}

Analysing the SEM model for the research model, the authors have found that the composite indexes are satisfactory. In specific, Chi-square $=2273.912 ; \mathrm{df}=652 ;$ Chi-square $/ \mathrm{df}=3.488(<5) ; \mathrm{P}=0.000 ; \mathrm{GFI}=0.829(>0.8) ; \mathrm{TLI}=0.864(>0.8)$; $\mathrm{CFI}=0.874(>0.8) ; \mathrm{RMSEA}=0.069(<0.08)$ (see Fig. 2$)$.

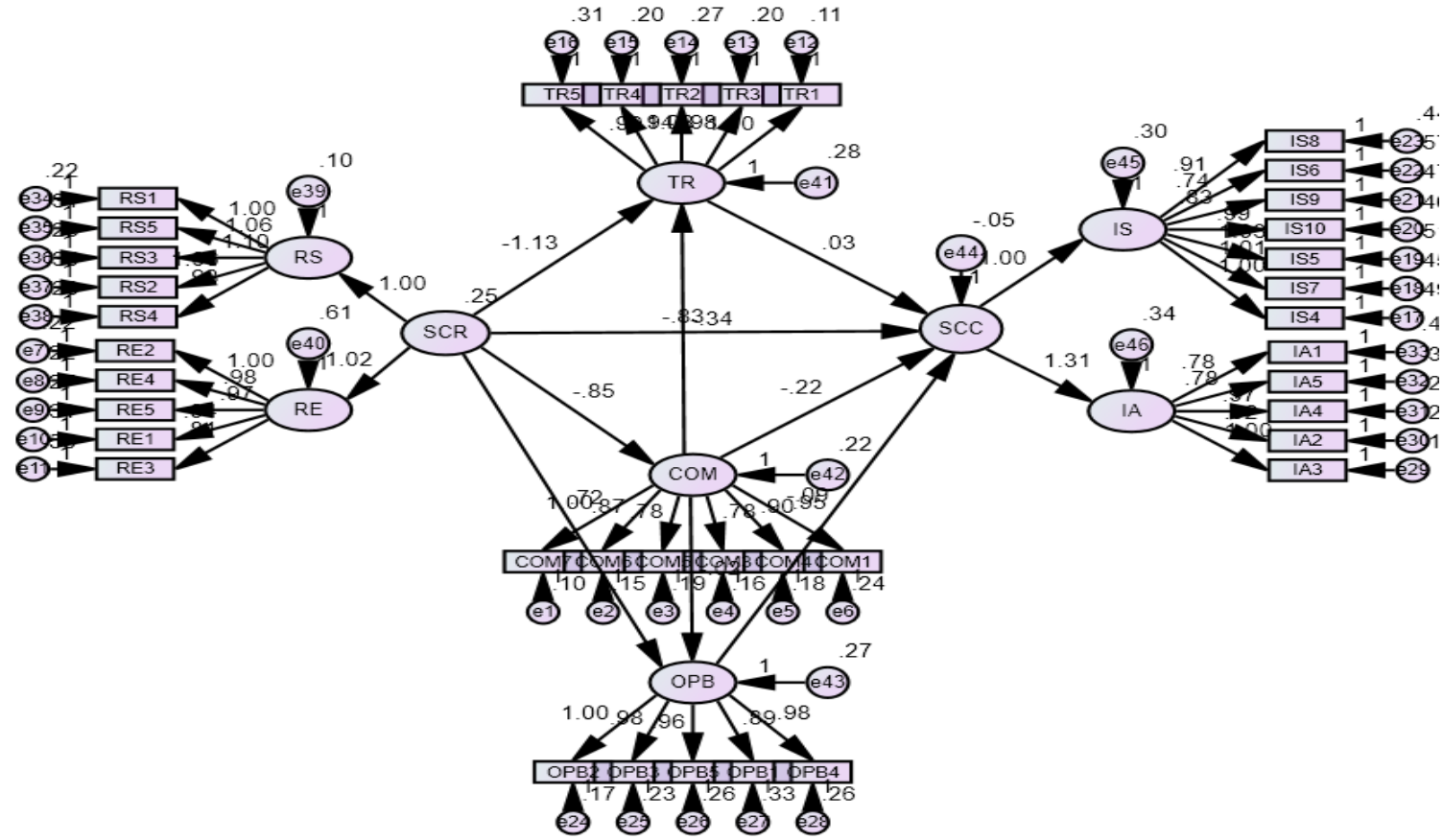

Fig. 2. SEM model analysis

The result of the estimation of the relationships in the model shows that the research model is appropriate. According to the test results, the hypotheses $\mathrm{H} 1, \mathrm{H} 2, \mathrm{H} 4, \mathrm{H} 6, \mathrm{H} 7$ are accepted while the hypotheses $\mathrm{H} 3, \mathrm{H} 5, \mathrm{H} 8$, and $\mathrm{H} 9$ are rejected.

Specifically, hypothesis H1 with a significance level $\mathrm{P}<0.05$ and regression weight of $-0.826(<0)$ is accepted. In other words, risk negatively affects the supply chain cooperation in the agriculture sector in Vietnam. This conclusion corresponds to the research works of Trkman and McCormack (2009); Calantone et al. (2003), etc.

Similarly, hypothesis $\mathrm{H} 2$ is accepted with a significance level $\mathrm{P}<0.05$ and regression weight is $-1.133(<0)$. Therefore, risks negatively impact the participant's trust in the agricultural supply chain in Vietnam, which is consistent with Frohlich and Westbrook (2001); Zsidisin (2003), etc.

Hypothesis $\mathrm{H} 3$ is rejected because the significance level is $0.641(>0.05)$. In other words, the participant's trust has no impact on the supply chain cooperation in the agriculture sector in Vietnam.

Hypothesis H4 is accepted with a significance level $\mathrm{P}<0.05$ and regression weight is $-0.849(<0)$. It concluded that risks negatively impact the participant's commitment to the agricultural supply chain in Vietnam. This result is also similar to the studies of Khan and Burnes (2007); Trkman and McCormack (2009), etc.

Hypothesis H5 is rejected because the significance level in the test is $0.003(<0.05)$ and regression weight is $-0.222(<0)$, which is contrary to the initial assumption. In other words, the participant's commitment has a negative relationship with the agricultural supply chain cooperation in Vietnam. This can be explained because of the dependent mentality of participants 
in the supply chain. They can take advantage of commitment to redeem their interests, not for the benefit of other parties. It affects the effectiveness of relationships, as well as the participant's business result.

Meanwhile, hypothesis H6 is accepted with a significance level $\mathrm{P}<0.05$ and regression weight is 0.719 ( $>0$ ). In other words, risk positively affects the participant's opportunistic behaviour in the agricultural supply chain in Vietnam, which is consistent with Chen \& Paulraj (2004); Tran et al. (2019), etc.

Similarly, hypothesis H7 is accepted because the significance level in the test is $0.030(<0.05)$ as well as the regression weight is $-0.094(<0)$. It proves the opportunistic behaviour of the participants negatively impacts the supply chain cooperation in the agriculture sector in Vietnam. This result is consistent with the studies of Zsidisin (2003); Trkman and McCormack (2009), etc.

The test result of Hypothesis H8 shows that the significance level is $<0.05$, the regression weight is $-0.335(<0)$. Hypothesis $\mathrm{H} 8$ is rejected, which is contrary to the initial assumption. In other words, commitment negatively influences the participant's trust in the agricultural supply chain in Vietnam. The cause is the participant's dependency mentality. They can take advantage of commitment to redeem their interests, which affects the effectiveness of relationships and trust of each participant in the supply chain.

Meanwhile, hypothesis H9 is also rejected because the significance level in the P-test was 0.739 ( $>0.05)$. Therefore, the conclusion is that commitment has no impact on the participant's opportunistic behaviour in the agricultural supply chain in Vietnam.

Thus, the research results show that risk has a direct and negative impact on supply chain cooperation and reduces the effectiveness of cooperative relationships. Moreover, it effects indirectly through the intermediary factors are the participant's commitment and opportunistic behaviour (see Table 7). These are meaningful contributions in theoretical and practical aspects and are the basis for further research works.

Table 7

SEM analysis results for relationships in the model

\begin{tabular}{ccccccc}
\hline Hypothesis & Relationship & Weight & S.E. & C.R. & P & Conclusion \\
\hline H1 & SCC $\leftarrow$ SCR & -0.826 & 0.182 & -4.540 & 0.000 & Accepted \\
H2 & TR $\leftarrow$ SCR & -1.133 & 0.149 & -7.601 & 0.000 & Accepted \\
H3 & SCC $\leftarrow$ TR & 0.026 & 0.057 & 0.466 & 0.641 & Rejected \\
H4 & COM $\leftarrow$ SCR & -0.849 & 0.083 & -10.183 & 0.000 & Accepted \\
H5 & SCC $\leftarrow$ COM & -0.222 & 0.076 & -2.922 & 0.003 & Rejected \\
H6 & OPB $\leftarrow$ SCR & 0.719 & 0.109 & 6.564 & 0.000 & Accepted \\
H7 & SCC $\leftarrow$ OPB & -0.094 & 0.043 & -2.174 & 0.030 & Accepted \\
H8 & TR $\leftarrow$ COM & -0.335 & 0.092 & -3.657 & 0.000 & Rejected \\
H9 & OPB $\leftarrow$ COM & -0.024 & 0.072 & -0.333 & 0.739 & Rejected \\
\hline
\end{tabular}

\subsection{Descriptive Statistical Analysis}

Thus, the test results have shown the relationship between risk and the supply chain cooperation in the agriculture sector and the role of mediating factors (the participants' commitment and opportunistic behaviour). To demonstrate these results and relate to reality, the authors have carried out descriptive statistical analysis and determined the average value of the factors.

Table 8

The results of statistical analysis describing the variables

\begin{tabular}{cccccc}
\hline Variables & N & Min & Max & Mean & Std. Deviation \\
\hline SCR & 518 & 1.00 & 4.30 & 1.9479 & 0.65884 \\
RS & 518 & 1.00 & 4.60 & 2.2158 & 0.66021 \\
RE & 518 & 1.00 & 5.00 & 1.6799 & 0.91191 \\
TR & 518 & 1.00 & 5.00 & 3.6158 & 0.70476 \\
COM & 518 & 1.00 & 5.00 & 3.9083 & 0.58125 \\
OPB & 518 & 1.00 & 5.00 & 2.4359 & 0.65625 \\
SCC & 518 & 1.74 & 4.90 & 3.6823 & 0.51771 \\
IS & 518 & 1.71 & 5.00 & 3.4782 & 0.63929 \\
IA & 518 & 1.00 & 5.00 & 3.8865 & 0.67547 \\
\hline
\end{tabular}

The statistical results show that with an average value of 3.9083, the participant's commitment to the Vietnamese agricultural supply chain is assessed at the highest level of all factors in the model. This figure proves the interest of organizations and businesses in Vietnam in strengthening the cooperative relationship in the agricultural supply chain. However, in some cases, 
some organizations/individuals can take advantage of this commitment to benefit their organizations/individuals without regard to whether the stakeholders' interest is affected or not. It will have a significant impact on the trust of the participants and the sustainable relationship in supply chain cooperation. In addition, the results of descriptive statistics also point out that the risk in the agricultural supply chain in Vietnam is currently quite low (average value is 1.9479). This figure is a positive signal, demonstrating a favourable environment for organizations to participate in the agricultural supply chain in Vietnam (see Table 8).

\section{Conclusions and Recommendations}

The study aims to test the direct and indirect effects of risk on supply chain cooperation in the agriculture sector in Vietnam. The result found that risk has impacted not only directly and negatively on the supply chain cooperation but also indirectly through intermediary factors, namely commitment and the participant's opportunistic behaviour. In addition, the study proves that in some cases, the participant's commitment and trust and the supply chain cooperation has a negative correlation, which stems from dependency mentality at work. The findings of this study play a significant role in both theoretical and practical contributions. Theoretically, the paper has demonstrated the relationship between risk and agricultural supply chain cooperation and the mediating part of the commitment and opportunistic behaviour. Practically, the test results have supported managers and policymakers to make policies to improve the effectiveness of the supply chain cooperation in the agriculture sector in Vietnam. Besides those contributions, the study also has certain limitations. Firstly, one of the limitations of the study is the convenience sampling method which reduces the controllability of the sample representativeness. Secondly, the research context is limited to the agricultural sector in Vietnam. Based on the obtained results, the article has guided the development direction in research conducted in other countries in the region and around the world. Based on the research results, the author proposes some recommendations to enhance the supply chain cooperation in the agriculture sector in Vietnam:

First of all, for risks in the supply chain, it is necessary to develop business strategies to strengthen supply chain cooperation, reduce risk from the environment in the agriculture sector. Exploit agricultural products suitable for each locality's strengths, stabilize and gradually expand markets as well as diversify export products. Support enterprises in building and registering product trademarks, collectives, and geographical indications of origin for main agricultural products. Strengthen cooperation between domestic producing households and enterprises in the chain of agriculture - service - industry products with investment cooperation models in production - purchasing - processing - consumption with the motto "sharing responsibility, risks and benefits".

Secondly, for the participant's trust in the supply chain, it is necessary to build understanding for members participating in the chain. Innovate the thinking of agricultural producers, especially farmers, in realizing the importance of supply chain cooperation and participation. Showing them the benefits of participating in the supply chain is a trend of all manufacturing industries, including agriculture.

Thirdly, for the commitment among participants in the supply chain, it is necessary to renovate the production organization in the processed materials production areas according to the production chain and value chain, based on linked development. In there, the processing enterprises play a pivotal role in forming and developing sustainable supply chains. Moreover, the enterprise needs to associate production with processing, preservation, and consumption according to the value chain to enhance added value for each locality's competitive product. Each member in the supply chain should sign legal contracts to ensure their interests and strengthen their commitment to purchasing agricultural raw materials and products. In addition, the breach of an economic contract is strictly penalized by the authorities.

Finally, for the participant's opportunistic behaviour in the supply chain, besides solutions to promote the supply chain cooperation and build trust among participants, there should be strict management policies to restrict individual acts without regard to the stakeholder's interest. Combine handling sanctions with propaganda measures for individuals and organizations to improve understanding of the importance of supply chain cooperation in the agriculture sector.

\section{References}

Boddy, D., Macbeth, D., \& Wagner, B. (2000). Implementing collaboration between organizations: An empirical study of supply chain partnering. Journal of Management Studies, 37(7), 1003-1019.

Bowersox, D.J., Closs, D.J., \& Stank, T.P. (2003). How to master cross-enterprise collab- oration. Supply Chain Management Review, 7(4), 18-27.

Bromiley, P., \& Cummings, L.L. (1995). Transaction Costs in Organizations with Trust. Research in Negotiation in Organizations, 5, 219-247.

Calantone, R., Garcia, R., \& Droge, C. (2003). The effects of environmental turbulence on new product development strategy planning. Journal of Product Innovation Management, 20(2), 90-103.

Cao, M., \& Zhang, Q. (2011). Supply chain collaboration: Impact on collaborative advantage and firm performance. Journal of Operations Management, 29(3), 163-180. 
Cavinato, J.L. (2004). Supply chain logistics risks: From the back room to the board room. International Journal of Physical distribution \& Logistics Management, 34(5), 383-387.

Chen, I.J., \& Paulraj, A. (2004). Towards a theory of supply chain management: the constructs and meansurement. Journal of Operations Managements, 22, 119-150.

Fawcett, S. E., Fawcett, A., Watson, B., \& Magnan, G. (2012). Peeking inside the black box: toward an understanding of supply chain collaboration dynamics. Journal of Supply Chain Management, 48(1), 44-72.

Frohlich, M.T., \& Westbrook, R. (2001). Arcs of integration: An international study of supply chain strategies. Journal of Operations Management, 19(2), 185-200.

Golicic, S. L., Foggin, J. H., \& Mentzer, J. T. (2003). Relationship magnitude and its role in interorganizational relationship structure. Journal of Business Logistics, 24(1), 57-75.

Hair, J.F., Anderson, R.E., Tatham, R.L., \& Black, W.C. (1998). Multivariate Data Analysis. th $^{\text {th }}$ ed., Upper Saddle River, NJ: Prentice Hall.

Juttner, U., Peck, H., \& Christopher, M. (2003). Supply chain risk management: Outlining an agenda for future research. International Journal of Logistics, 6(4), 197-210.

Katsikeas, C.S., Dionysis, S., \& Daniel C. (2009). Developing successful trust-Based international exchange relationships. Journal of International Business Studies, 40(1), 132-155.

Kettinger, W.J., Lee, C.C., \& Lee, S. (1995). Global Measures of Information Services Quality: A Cross-National Study. Decision Sciences, 26(5), 569-588.

Khan, O. \& Burnes, B. (2007). Risk and supply chain management: creating a research agenda. The International Journal of Logistics Management, 18(2), 197-216.

Kocoglu, I., Imamoglu, S.Z., Ince, H., \& Keskin, H. (2011). The effect of supply chain integration on information sharing:Enhancing the supply chain performance. Social and Behavioral Sciences, 24, 1630-1649.

Kwon, I.W.G., \& Suh, T. (2004). Factors affecting the level of trust and commitment in supply chain relationships. Journal of Supply Chain Management, 40(2), 4-14.

Lambert, D.M., Stock, J.R., \& Ellram, L.M. (1998). Fundamentals of Logistics Management, Boston, MA: Irwin/McGrawHill.

Lee, H.L., \& Whang, S. (2000). Information sharing in a supply chain. International Journal of Technology Management, 20(3), 373-387.

Manthou, V., Vlachopoulou, M., \& Folinas, D. (2004). Virtual e-Chain (VeC) model for supply chain collaboration. International Journal of Production Economics, 87(3), 241-250.

Mentzer, J.T., DeWitt, W., Keebler, J.S., Min, S., Nix, N.W., \& Smith, C.D. (2001). Defining supply chain management. Journal of Business Logistics, 22(2), 1-25.

Morgan, R.M. \& Hunt, S.D. (1994). The commitment-trust theory of relationship marketing. Journal of Marketing, 53(3), 20-38.

Nguyen, T.M.P., Tran, Q.B., Do, D.T. \& Tran, D.L. (2020). Impact of corporate social responsibility toward employees on business performance: The case of Vietnam, Uncertain Supply Chain Management, 8(3), 589-598.

Nyaga, G., Whipple, J., \& Lynch, D. (2010). Examining supply chain relationships: do buyer and supplier perspectives on collaborative relationships differ? Journal of Operations Management, 28(2), 101-114.

Samaddar, S., \& Kadiyala, S.S. (2006). An analysis of interaorganisational resource sharing decisions in collaborative knowledge creation. European Journal of Operational Research, 170, 192-210.

Sheu, C., Yen, H.R., \& Chae, D. (2006). Determinants of supplier-retailer collaboration: evidence from an international study. International Journal of Operations and Production Management, 26(1), 24-49.

Stank, T.P., Keller, S.B., \& Daugherty, P.J. (2001). Supply chain collaboration and logistical service performance. Journal of Business Logistics, 22(1), 29-48.

Taylor, P.D., Lenore, F., Kringen, H., \& Gray, M. (1993). Connectivity is a vital element of landscape structure. Nordic Society Oikos, 68, 571-573.

Togar, M.S., \& Ramaswami, S. (2005). The collaboration index: a measure for supply chain collaboration. International Journal of Physical Distribution \& Logistics Management, 35(1), 44-62.

Torres, M.A.S. (2012). Determinants of the quality in the relationship of the suppy chain, PhD thesis, Universidad Del Turabo.

Tran, Q.B., Nguyen, T.T.C., Nguyen, T.M.P., Tran, D.L., Nguyen, A.T., \& Dang, Q.T. (2019). The Effects of Risks in Agricultural Supply Chain Management on Business Performance: A Case Study in Vietnam. AgBioForum, 21(3), 2334.

Trkman, P., \& McCormack, K. (2009). Supply Chain Risk in Turbulent Environments-A Conceptual Model for Managing Supply Chain Network Risk. International Journal of Production Economics, 119(2), 247-258.

Uzzi, B. (1997). Social structure and competition in interfirm networks: The paradox of embeddedness. Administrative Science Quarterly, 42(1), 35-67.

Vereecke, A., \& Muylle, S. (2006). Performance improvement through supply chain collaboration in Europe. International Journal of Operations \& Production Management, 26(11), 1176-1198.

Wagner, S. \& Bode, C. (2008). An empirical examination of supply chain performance along several dimensions of risk. Journal of Business Logistics, 29(1), 307-325. 
Walter, A. (2003). Relationship-specific factors influencing supplier involvement in customer new product development. Journal of Business Research, 56(9), 721-733.

Wuyts, S., \& Geyskens, I. (2005). The Formation of Buyer-Supplier Relationships: Detailed Contract Drafting and Close Partner Selection. Journal of Marketing, 69(4), 103-117.

Zhao, L., Sun, L., \& Zhao, X. (2013). The impact of supply chain risk on supply chain integration and company performance: a global investigation. Supply chain management: An International Journal, 182, 115-131.

Zsidisin, G.A. (2003). A grounded definition of supply risk. Journal of Purchasing and Supply Management, 9(5), $217-224$. 
(C) 2022 by the authors; licensee Growing Science, Canada. This is an open access article distributed under the terms and conditions of the Creative Commons Attribution (CCBY) license (http://creativecommons.org/licenses/by/4.0/). 